\title{
Electrocardiographic interference and conductance volume measurements
}

\author{
Simon P. McGuirk ${ }^{1,2}$, Dan Ewert ${ }^{3}$, David J. Barron ${ }^{1}$, John H. Coote $^{2}$ \\ ${ }^{1}$ Department of Cardiac Surgery, Birmingham Children's Hospital, Birmingham, UK; ${ }^{2}$ School of Clinical and Experimental Medicine, \\ University of Birmingham, Birmingham, UK; ${ }^{3}$ Department of Electrical and Computer Engineering, North Dakota State University, \\ Fargo, USA. \\ Email: simon.mcguirk@,nhs.net
}

Received 1 February 2009; revised 1 July 2009; accepted 16 July 2009.

\section{ABSTRACT}

The conductance catheter technique enables continuous ventricular volume measurements based on the electrical conductance of blood within the ventricular cavity. However, ventricular excitation also produces a measurable electrical signal within the ventricular cavity. This study was undertaken to investigate the relationship between the ventricular electrogram and conductance volume measurements in a physical model of the left ventricle without parallel conductance. The ventricular electrogram was simulated with an ECG signal, $E C G_{\text {input }}$ connected to two ring electrodes within the model ventricle. Conductance volume measurements were made with and without $E C G_{\text {input }}$. The difference between these measurements, $G_{E C G}(t)$, represented the conductance volume due to $E C G_{\text {input }} \cdot G_{E C G}(t)$ varied as a function of the first-derivative of $E C G_{\text {input }}$ with respect to time $\left(r^{2}=0.92, P<0.001\right) . G_{E C G}(t)$, This primarily affected volume measurements during ventricular depolarisation; during this phase the volume measurement error varied widely between $-12 \%$ and $+9 \%$. As a result, end-diastole could not be reliably identified on the pressure-volume loop. The accuracy of conductance volume measurements during late diastole and early isovolumic contraction are substantially affected by the ventricular electrogram. This may result in a significant error in end-diastolic volume estimates, which has important implications for the quantitative assessment of ventricular function including, in particular, the assessment of chamber compliance.

Keywords: Volume Measurement; Conductance Catheter; Electrocardiogram; Ventricular Electrogram

\section{INTRODUCTION}

The assessment of ventricular function is fundamentally important for the evaluation of patients with known or suspected heart disease. Analysis of left ventricular (LV) volume in the time and pressure domains allows systolic and diastolic function to be separately quantified. The conductance catheter technique was developed to continuously measure ventricular volume in real-time $[1,2]$. These measurements are recorded simultaneously with intraventricular pressure measurements to provide instantaneous pressure-volume data [3].

The conductance catheter technique is associated with two, well known sources of error. Firstly, the current density generated by the conductance catheter is not uniformly distributed throughout the ventricular cavity $[4,5,6]$. This results in a non-linear conductance-absolute volume relationship $[2,4,7]$. Conductance volume measurements must be corrected with a calibration coefficient, $\alpha$ [8]. Secondly, the tissues and fluid surrounding the ventricular cavity also contribute to the conductance signal $[2,8]$. This results in an offset in the conductanceabsolute volume relationship, called parallel conductance. In practice, conductance volume measurements are usually calibrated for parallel conductance using the hypertonic saline method in order to derive accurate ventricular volume measurements [8].

In our paediatric clinical experience, we have observed that the pattern of LV volume measurements is frequently abnormal. The conductance volume measurements are characterised by a narrow upward spike followed by a narrow downward spike during late diastole without any commensurate change in LV pressure (Figures 1A and 1B). This alters the shape of the pressure-volume loop, with the loss of the normal lower right-hand corner (Figure 1D). To our knowledge, this abnormal conductance volume pattern has not previously been described. However, we understand that similar 


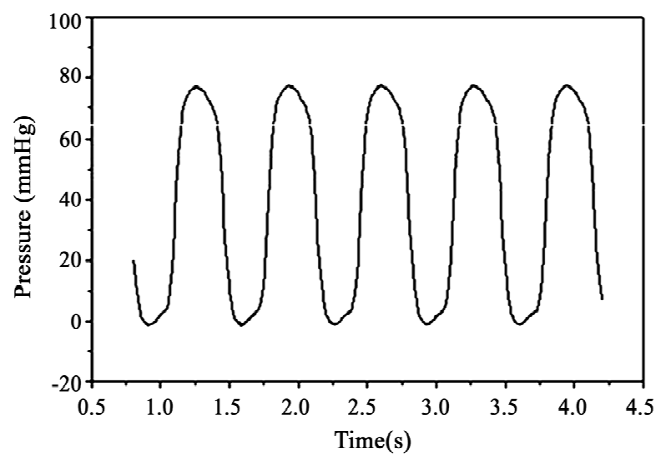

(a)

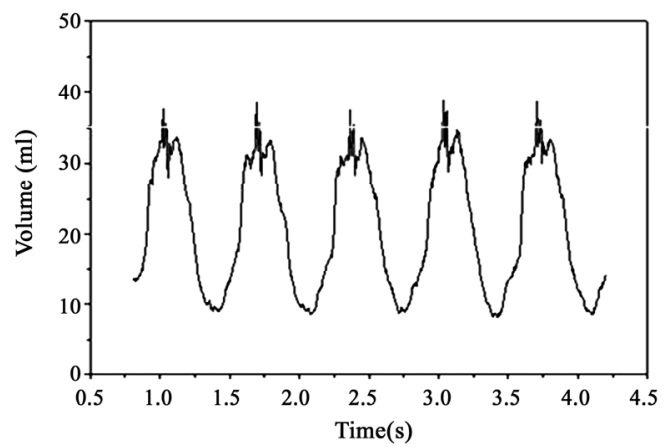

(b)

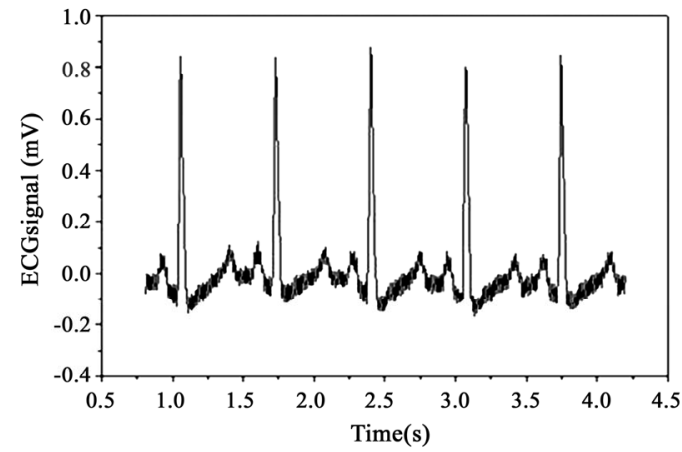

(c)

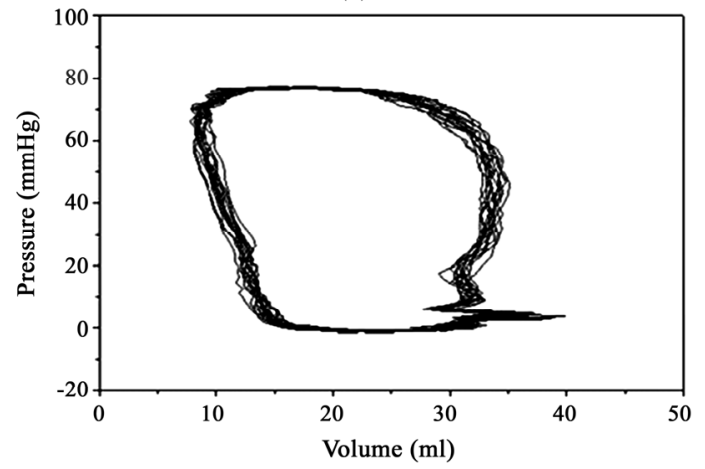

(d)

Figure 1. Time-varying pressure (A), conductance volume (B) and surface electrogram (C) signals obtained in a 6 year-old child with tricuspid atresia. The corresponding pressure- conductance volume loop for the same child (D) was developed by plotting the instantaneous pressure against the corresponding conductance volume. findings have been observed in other patient groups, particularly in patients with a permanent pacemaker [personal communication, Professor M.P. Frenneaux, Department of Cardiovascular Sciences, University of Birmingham, UK; Dr P. Steendijk, Department of Cardiology, Leiden University Medical Center, The Netherlands].

We observed that the abnormal LV conductance volume measurements occurred synchronously with the QRS complex on the surface electrocardiogram (ECG; Figure 1C). We hypothesised that this abnormal LV conductance measurement may represent the effect of ventricular excitation on conductance volume measurements, which is superimposed on the normal ventricular volume cycle. This study was undertaken to examine the relationship between the ventricular electrogram and conductance volume measurements in a physical model of the left ventricle without parallel conductance. In addition, we sought to determine how this relationship was influenced by changes in electrical resistance across the model ventricle.

\section{METHODS}

\subsection{Model Ventricle}

This study used the physical model of the left ventricle previously developed by this aboratory [9] and described in the accompanying paper [10]. In summary, this consisted of an ellipsoid latex balloon enclosed in a pressurised Perspex chamber. The chamber was filled with distilled water and hydraulically pressurised with an intra-aortic balloon pump (IABP; Datascope Medical Co. Ltd, Huntingdon, UK) connected to two $25 \mathrm{ml}$ intra-aortic balloon catheters in parallel. A patient simulator (Bioma Research Inc, Quebec, Canada) was used to trigger the IABP console at a predetermined rate $\left(60\right.$ beats $\left.\cdot \mathrm{min}^{-1}\right)$.

Inflation of the intra-aortic balloon catheters displaced the stroke volume $(\mathrm{SV}, 50 \mathrm{ml})$ from the model ventricle through a 2/2-way solenoid valve (Bürkert $\mathrm{GmbH}$, Ingelfingen, Germany) into a calibrated measuring cylinder at the top of the model ventricle. Deflation of the IABP balloon catheters caused ventricular pressure to fall, which allowed the latex balloon to refill. Electronic circuitry was used to control the opening and closure times of the solenoid valve in order to simulate different contraction patterns.

The latex balloon was $13 \mathrm{~cm}$ in length and had a maximal volume at atmospheric pressure of $500 \mathrm{ml}$. The balloon was filled with $385-500 \mathrm{ml}$ of buffered saline solution $(V)$ at room temperature. The saline concentration was varied between $0.18-1.57 \%$. The resistivity $(\rho$; conductivity $^{-1}$ ) of these solutions was measured before each test using a dedicated measuring cuvette (CD Leycom, Zoetermeer, The Netherlands). The resistivity ranged between $37 \pm 0.8$ to $330 \pm 0.5 \Omega \mathrm{cm}$. 
Ventricular depolarisation was simulated using a fixed output ECG signal, $E C G_{\text {input }}$, from the patient simulator (maximum $150.4 \pm 0.1 \mathrm{mV}$, minimum $-35.8 \pm 0.2 \mathrm{mV}$ ). This was connected, via a resistor $(200 \Omega)$, to a dipole within the latex balloon. This dipole consisted of two copper ring electrodes (diameter $30 \mathrm{~mm}$, depth $5 \mathrm{~mm}$ and thickness $1 \mathrm{~mm}$ ) that were positioned perpendicular to the long-axis of the balloon. The in-series resistor was adjusted so that the signal range of the intracavitary electrogram $(E C G c)$ in the model ventricle was equivalent to that observed in vivo $(\sim 1 \mathrm{mV})$.

In vivo, the intracavitary electrogram primarily reflects the pattern of ventricular depolarisation and repolarisation in the endocardium of the ventricle [11]. The position of the endocardium relative to the long-axis of the ventricle will vary as the ventricular volume changes during the cardiac cycle. This effect was simulated by altering the distance between the two electrodes of the dipole. The distance between the two electrodes $(D)$ was varied between $3 \mathrm{~cm}$ and $11.5 \mathrm{~cm}$ such that both electrodes remained equidistant from the centre of the balloon.

\section{CONDUCTANCE CATHETER}

The principle of the conductance catheter technique for measuring LV volume has been described elsewhere [8]. The details of the conductance catheter used in this study are described in the accompanying paper [10]. The catheter measured seven time-varying segmental conductance signals, $G_{i}(t)$. As parallel conductance is negligible in our model, the total conductance volume, $Q(t)$, was determined using the following formula:

$$
Q(t)=L^{2} \cdot \rho \cdot\left[\sum_{i=1}^{7} G_{i}(t)\right]
$$

where $\rho$ is the blood resistivity and $L$ is the inter-electrode distance. The dimensionless calibration coefficient, $\alpha_{V(t)}$ was calculated from conductance volume measurements without the ECG signal by dividing the conductance-derived volume measurement by the absolute volume at either end-diastole or end-systole:

$$
\alpha_{V(t)}=\frac{Q_{E D}}{V_{E D}} \text { or } \frac{Q_{E S}}{V_{E S}}
$$

We have previously demonstrated that the calibration coefficient, $\alpha_{V(t)}$ varies as a non-linear function of the absolute ventricular volume [10]. We used this non-linear $\alpha_{V(t)}$-volume relation to calibrate conductance volume measurements:

$$
V_{g}(t)=\frac{1}{\alpha_{V V}} \cdot Q(t)
$$

where $\alpha_{V V}$ is the $\alpha_{V(t)}$-volume relation [10].
Instantaneous pressure within the model ventricle was measured using a high-fidelity solid-state micromanometer laterally positioned between electrodes 5 and 6 within the conductance catheter. This pressure signal was amplified using a combined amplifier-interface unit (PCU-2000; Millar Instruments, Houston, TX, USA) and statically calibrated using a separate fluid-filled catheter-manometer system.

The cavitary electrogram, $E C G c$ was measured as part of the conductance catheter technique. The conductance signal between electrodes 5 and 6 was measured, amplified and filtered using a second-order filter with a high cut-off frequency $(-3 \mathrm{~dB} ; 125 \mathrm{~Hz})$ in order to derive the $E C G c$ [personal communication; CD Leycom, Zoetermeer, The Netherlands].

\section{ECG INTEREFERENCE}

The conductance signal was measured either with, $G_{i}^{+}(t)$, or without the ECG signal, $G_{i}^{-}(t)$. ECG interference, $G_{E C G}(t)$ was calculated as the difference between these two conductance signals:

$$
G_{E C G}(t)=\sum_{i=1}^{7} G_{i}^{+}(t)-\sum_{i=1}^{7} G_{i}^{-}(t)
$$

The difference between calibrated volume measurements made with, $V_{g}^{+}(t)$ and without the ECG signal, $V_{g}^{-}(t)$ was expressed as a percentage of the $V_{g}^{-}(t)$ signal:

$$
\Delta V_{E C G}=\frac{\left[V_{g}^{+}(t)-V_{g}^{-}(t)\right]}{V_{g}^{-}(t)}
$$

\section{EXPERIMENTAL DATA}

Analogue signals representing 7 segmental conductance signals, the pressure within the model ventricle, and both $E C G_{\text {input }}$ and $E C G c$ were all digitised at 12-bit accuracy and a sample frequency of $250 \mathrm{~Hz}$. End-diastole and endsystole were retrospectively identified. End diastole was defined as the R wave on the ECG and end-systole was defined as the point immediately prior to IABP circuit deflation.

The effect of intracavitary volume $(V)$, resistivity of the saline solution $(\rho)$ and inter-electrode distance $(D)$ on the intracavitary electrogram and conductance volume measurements were examined in turn. This involved a series of experiments, in which one variable was altered incrementally while the other two variables remained unchanged. This process was repeated until the data from the entire range was obtained (see above).

Each experiment was conducted under steady-state conditions and data from 5 consecutive cycles were analysed. The average within-experiment standard deviation was 0.71 $\mathrm{ml}$ and, at its worst, this represented $<0.5 \%$ of the total conductance volume. All subsequent analyses were therefore based on the average data from each experiment. 


\section{DATA ANALYSIS}

Data were analysed using SPSS for Windows (v12, SPSS Inc., Chicago, Il, USA). Data are expressed as mean \pm SD and comparative analyses have been made using the t-test. The relationship between the $E C G_{\text {input }}$, $E C G c$ and the ECG interference pattern was evaluated by least squares linear regression based on fractional polynomials of the data. The intracavitary volume, resistivity of the saline solution and the inter-electrode distance were included as covariables in the regression analyses. The coefficients of the linear regression analyses, in both the overall and covariance analyses, are expressed as mean \pm standard error and a probability, $P<0.05$, was taken to represent statistical significance. The "goodness of fit" of the prediction equation was assessed as the square of the correlation between dependent and significant independent variables.

\section{RESULTS}

\subsection{Comparison between ECG Signal and Cavitary Electrogram}

The ECG signal, $E C G_{\text {input }}$, consisted of $\mathrm{P}, \mathrm{Q}, \mathrm{R}, \mathrm{S}$ and $\mathrm{T}$ deflections that resembled the normal lead II electrocardiogram (Figure 2A). The $\mathrm{P}$ wave was $84 \mathrm{~ms}$ in duration with a peak of $6.2 \mathrm{mV}(40 \mathrm{~ms})$. The $\mathrm{P}$ wave represented approximately half the PR interval $(156 \mathrm{~ms})$. The positive QRS complex had an overall duration of $84 \mathrm{~ms}$, with a maximum at $192 \mathrm{~ms}(150.4 \mathrm{mV})$ and two minima at $164 \mathrm{~ms}(-26.4 \mathrm{mV})$ and $224 \mathrm{~ms}(-34.1 \mathrm{mV})$. The ST segment was isoelectric $(-8.2 \mathrm{mV})$ and $36 \mathrm{~ms}$ long. The duration of the $\mathrm{T}$ wave was $236 \mathrm{~ms}$, with a peak of 41.4 $\mathrm{mV}$ (408 ms). Finally, the QT interval and TP segment were both isoelectric and $120 \mathrm{~ms}$ and $468 \mathrm{~ms}$ long, respectively.

The $E C G c$ signal resembled the $E C G_{\text {input }}$ signal turned upside down, with an inverted $\mathrm{P}$ wave, an $\mathrm{rSR}^{\prime}$ wave and an inverted T wave (Figure 2B). The overall relationship between the two signals was best approximated by a mathematical model in which the $E C G c$ signal was inversely proportional to the $E C G_{\text {input }}$ signal ( $\mathrm{r} 2=0.74$, $P<0.001)$ :

$$
E C G c(t)=\beta_{0}-\beta_{1} \cdot E C G_{\text {input }}(t)
$$

Although the $E C G_{\text {input }}$ and $E C G c$ signals were similar, they were not identical There were differences in timing and amplitude of the two signals. The ECGc $\mathrm{P}$ and $\mathrm{S}$ wave minima and the $\mathrm{R}$ wave peak occurred either synchronously or within one data point (i.e. $4 \mathrm{~ms}$ ) of the corresponding points on the $E C G_{\text {input }}$ signal. By contrast, the $E C G c \mathrm{R}^{\prime}$ wave peak and the $\mathrm{T}$ wave misnimum were $12 \mathrm{~ms}$ and $32 \mathrm{~ms}$ earlier than the corresponding points on the $E C G_{\text {input }}$ signal. The $E C G c \mathrm{R}^{\prime}$ wave peak was also disproportionately pronounced compared to the corresponding $\mathrm{S}$ wave of the $E C G_{\text {input }}$ signal. The $E C G c$ $\mathrm{R}^{\prime}-\mathrm{S}$ wave ratio was $-0.51 \pm 0.03$ whereas the $E C G_{\text {input }}$ $\mathrm{S}-\mathrm{R}$ wave ratio was $-0.17 \pm 0.02(P<0.001)$. In addition, the $E C G c$ did not accurately reproduce the isoelectric phases of the $E C G_{\text {input }}$ signal. During the $\mathrm{PR}, \mathrm{R}^{\prime} \mathrm{T}$ and TP segments, the ECGc signal was initially elevated and decreased progressively towards the baseline signal.

In the covariance analyses, the intercept value $(\beta 0)$ varied as a linear function of inter- electrode distance $(P<0.05)$, but was not affected by variation in the other two factors. By contrast, the linear regression coefficient $(\beta 1)$ varied as the inverse function of intracavitary volume and as a direct function of inter-electrode distance and resistivity of the solution (all $P<0.05$ ).

When these effects are combined, the relationship between $E C G c$ and $E C G_{\text {input }}$ was influenced by the inter-electrode distance (intercept value) and by the total resistance of the volume conductor (Eq. $\left.7 ; \mathrm{r}^{2}=0.65\right)$ :

$$
E C G c(t)=\beta_{2}+\left(\beta_{3} \cdot D\right)+\left[\beta_{4} \cdot\left(\frac{D \cdot \rho}{V}\right) \cdot E C G_{\text {input }}(t)\right]
$$

where $\beta_{2}=3.66 \pm 0.01 ; \beta_{3}=7.29 \cdot 10^{-3} \pm 1.53 \cdot 10^{-3}$ and $\beta_{4}$ $=-7.00 \cdot 10^{-3} \pm 0.06 \cdot 10^{-3}(P<0.05$ for each coefficient $)$.

\subsection{Comparison between ECG Interference and ECG Input Signals}

The ECG interference signal, $G_{E C G}(t)$ was characterised by a low amplitude biphasic $\mathrm{P}$ wave; a high amplitude equiphasic qRSr' complex; and a low-amplitude biphasic $\mathrm{T}$ wave (Figure 2C). Each phase of the $G_{E C G}(t)$ signal was synchronous with the $\mathrm{P}$ wave, QRS complex and $\mathrm{T}$ wave of the ECG signal, respectively.

The amplitude of the $G_{E C G}(t)$ has been described as a percentage of the maximum $G_{E C G}(t)$ signal from the isoelectric line. The $G_{E C G}(t) \mathrm{P}$ wave had a sine wavelike appearance with an initial upward deflection immediately followed by a downward deflection of comparable duration and amplitude. The maximum and minimum $G_{E C G}(t)$ P wave signals were $4.0 \pm 2.6 \%(28$ $\mathrm{ms})$ above and $4.4 \pm 2.6 \%(64 \mathrm{~ms})$ below the isoelectric line. The spiked wave $G_{E C G}(t) \mathrm{qRSr}$ ' complex had two maxima at $180 \mathrm{~ms}$ (R wave; $100 \pm 3 \%$ ) and $232 \mathrm{~ms}\left(\mathrm{r}^{\prime}\right.$ wave; $22 \pm 3 \%$ ) and two minima at $160 \mathrm{~ms}$ (q wave; $-24 \pm 3 \%$ ) and $204 \mathrm{~ms}$ (S wave; $-107 \pm 3 \%$ ). The $G_{E C G}(t) \mathrm{q}$ and R waves occurred $32 \mathrm{~ms}$ and $12 \mathrm{~ms}$ before the $E C G_{\text {input }} \mathrm{R}$ wave whereas the $G_{E C G}(t) \mathrm{S}$ and $\mathrm{r}^{\prime}$ waves occurred $12 \mathrm{~ms}$ and $40 \mathrm{~ms}$ after the $E C G_{\text {input }} \mathrm{R}$ wave. The $G_{E C G}(t)$ T wave had a similar overall appearance to the $G_{E C G}(t)$ P wave with an initial upward deflection immediately followed by an equivalent downward deflection. The maximum and minimum $G_{E C G}(t)$ T wave 


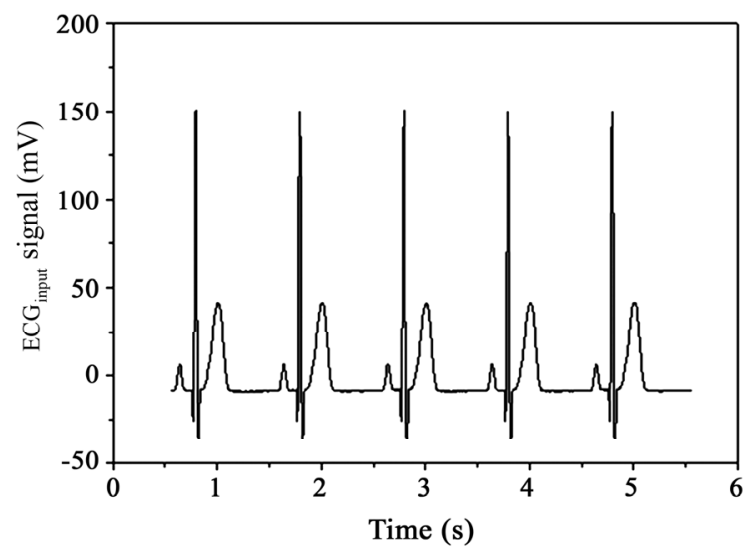

(a)

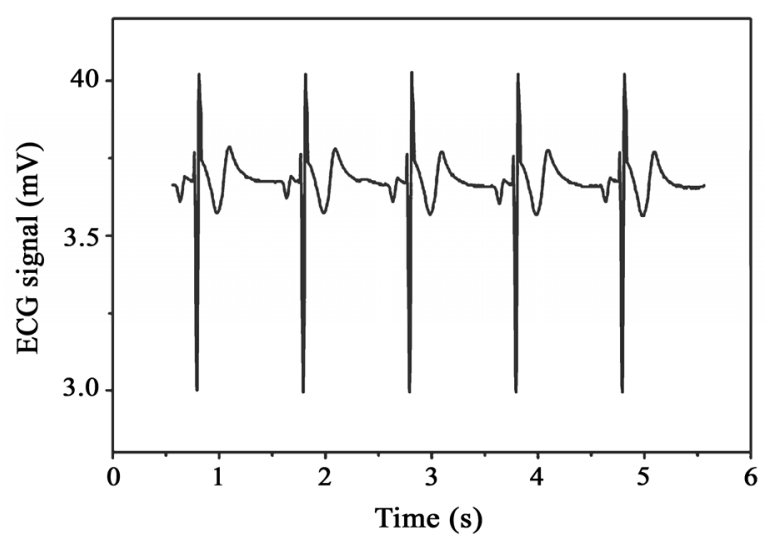

(b)

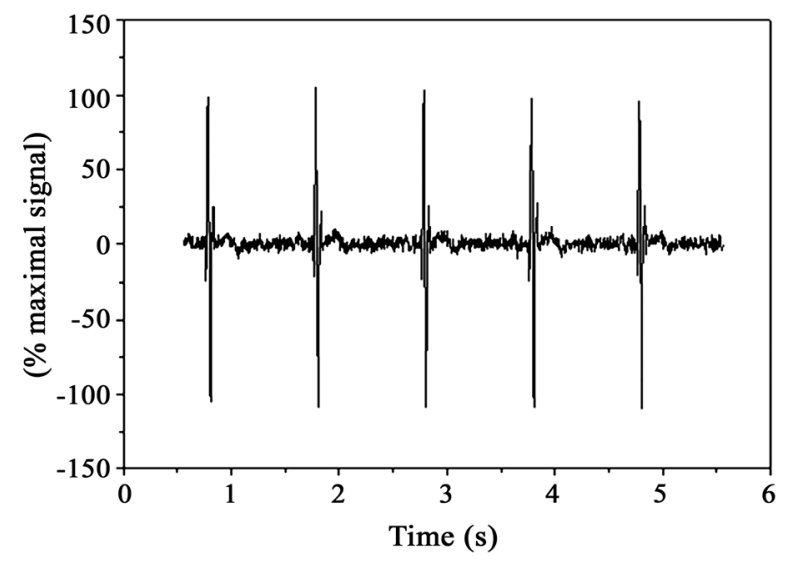

(c)

Figure 2. The ECG signal $\left(E C G_{\text {input }} ; \mathrm{A}\right)$, cavitary electrogram $(E C G c ; \mathrm{B})$ and ECG interference $\left(G_{E C G}(t) ; \mathrm{C}\right)$ signals versus time.

signals were $4.4 \pm 2.6 \%$ (352 ms) and $4.8 \pm 2.6 \%(452 \mathrm{~ms})$ below the isoelectric line and occurred $80 \mathrm{~ms}$ and $180 \mathrm{~ms}$ after the start of the $E C G_{\text {input }}$ T wave, respectively.

The relationship between $G_{E C G}(t)$ and $E C G_{\text {input }}$ was well approximated $\left(\mathrm{r}^{2}=0.92, P<0.001\right)$ by a regression equation in which the interference signal varied proportionally to the first-derivative of $E C G_{\text {input }}$ with respect to time:

$$
G_{E C G}(t)=\beta_{0}+\beta_{1} \cdot d E C G_{\text {input }}(t)
$$

In the covariance analyses, the intercept $\left(\beta_{0}\right)$ values varied as a linear function of the interelectrode distance $(P<0.05)$, but was not affected by variation in the other two factors. By contrast, the linear regression coefficients $\left(\beta_{1}\right)$, varied as a function of the intracavitary volume; and as the inverse function of both the inter-electrode distance and the resistivity of the solution (all $P<0.05$ ).

Overall, the relationship between $G_{E C G}(t)$ and the first derivative of $E C G_{\text {input }}$ varied as a function of the inter-electrode distance and the conductivity of the volume conductor (Eq. 9; $\left.\mathrm{r}^{2}=0.88\right)$ :

$$
G_{E C G}(t)=\left(\beta_{0} \cdot D\right)+\left[\beta_{1} \cdot\left(\frac{V}{D \cdot \rho}\right) d E C G_{\text {input }}(t)\right]
$$

where $\beta_{0}=1.49 \cdot 10^{-3} \pm 0.39 \cdot 10^{-3}$ and $\beta_{1}=6.07 \cdot 10^{-3} \pm$ $0.38 \cdot 10^{-3}$ ( $P<0.05$ for both coefficients).

\subsection{ECG Interference and Calibrated Conductance Volume Measurements}

For the purposes of this simulation, the inter-electrode distance was assumed to change in accordance with the instantaneous volume within the latex balloon. The inter-electrode distance was estimated as the maximal short-axis diameter of the spheroid, which varied from7.0 $\mathrm{cm}\left(V_{E S}=335 \mathrm{ml}\right)$ to $8.6 \mathrm{~cm}\left(V_{E D}=500 \mathrm{ml}\right)$. Calibrated conductance volume measurements with the ECG signal, $V_{g}^{+}(t)$ were compared against synchronous calibrated conductance volume measurements without the ECG signal, $V_{g}^{-}(t)$.

A representative example of calibrated conductance volume measurements with and without the ECG signal is illustrated in Figure 3. The $V_{g}^{-}(t)$ signal had a smooth, sinusoidal pattern that varied throughout the model heart cycle. The $V_{g}^{+}(t)$ signal was broadly similar, but had an additional spiked-wave pattern that coincided with the simulated ventricular depolarisation. The difference between the two ventricular volumes measurements, $\Delta V_{E C G}$ during this phase of the cardiac cycle varied between $-12 \%$ (i.e. an underestimation) and $+9 \%$. By contrast, the difference during the remainder of the cardiac cycle varied only slightly from -0.3 to $+0.9 \%$.

The pressure-volume loop obtained with the $V_{g}^{-}(t)$ signal had a quadrilateral shape with four distinct phases (Figure 4). End-diastole and end-systole were each identifiable as the single pressure-volume point at the lower right-hand and upper left-hand corners, respectively. The ECG interference pattern altered the shape of the pressure-volume loop, primarily affecting the late filling and early isovolumic contraction phases. As a result, end-diastole 




(a)

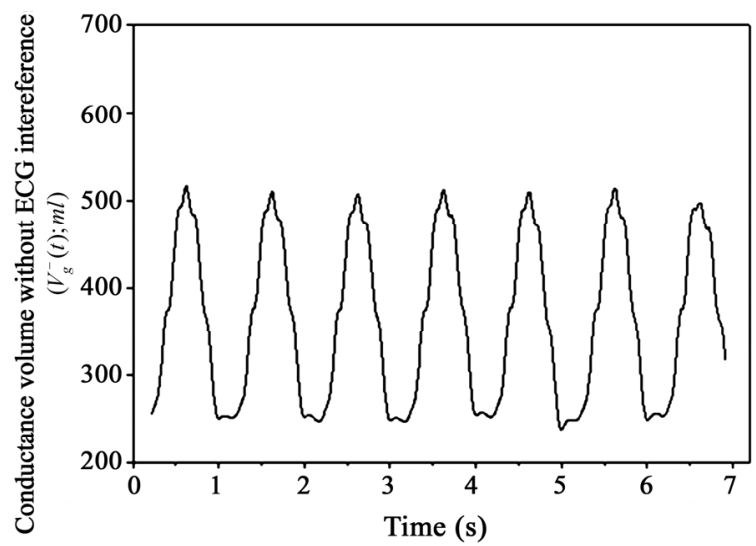

(b)

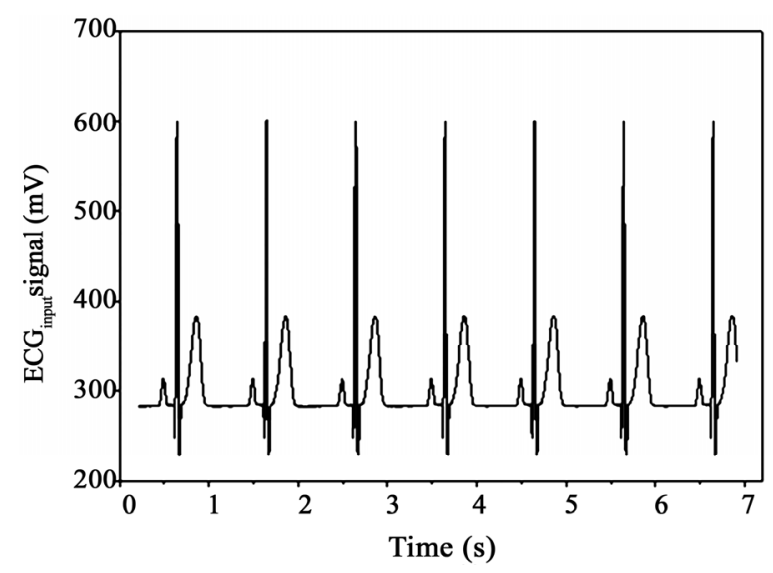

(c)

Figure 3. Calibrated conductance volume measurements versus time. Conductance volume measurements were made with $\left(V_{g}^{+}(t) ; \mathrm{A}\right)$ and without ECG interference $\left(V_{g}^{-}(t) ; \mathrm{B}\right)$ versus time. The ECG signal (ECGinput) has been plotted $(\mathrm{C})$ for comparison.

could not be reliably identified (Figure 4).

Comparable results were obtained under all experimental conditions. Increasing the end-diastolic volume from $385 \mathrm{ml}$ to $500 \mathrm{ml}$ did not significantly change the discrepancy between the two ventricular volume measurements. While increasing the resistivity from $37 \Omega \cdot \mathrm{cm}$ to $330 \Omega \cdot \mathrm{cm}$ increased the median measurement discrepancy slightly, from $+0.2 \%$ to $+1.8 \%$, it did not significantly alter the maximal range of the discrepancy.

\section{DISCUSSION}

The conductance catheter technique is an established method that enables continuous volume measurements based on the electrical conductance of the intraventricular blood pool. This study has demonstrated that other electrical signals within the ventricular cavity alter the measured conductance. This produces a conductance signal "artefact", which varies as a function of the first-derivative of the additional electrical signal. This artefact represents a novel and additional source of error that potentially affects the accuracy of ventricular volume measurements made using the conductance catheter technique.

Ventricular depolarisation and repolarisation cause a measurable electrical signal within the ventricular cavity [12]. In the present study, a simulated ventricular electrogram produced a biphasic signal with a highamplitude spiked wave pattern that coincided with the QRS complex and a comparatively low-amplitude sine wave- like pattern during the $\mathrm{T}$ wave. This signal was associated with a conductance volume measurement error that ranged between a $12 \%$ volume underestimation to a $9 \%$ volume overestimation. The entire range of this measurement discrepancy occurred within a $24 \mathrm{~ms}$ period during simulated ventricular depolarisation. By contrast, simulated repolarisation was associated with a small, clinically unimportant measurement error. The precise pattern, will vary with the morphology of ventricular electrogram $[12,13,14]$. The precise ECG interference pattern, $G_{E C G}(t)$ will vary with the morphology of ventricular electrogram $[12,13,14]$. Nevertheless, these in



Figure 4. Pressure-conductance volume loop from the model ventricle. Conductance volumemeasurements were made with $\left(V_{g}^{+}(t)\right.$; black line) or without ECG interference $\left(V_{g}^{-}(t)\right.$; grey dashed line). 
vitro findings are consistent with our previously unreported clinical findings.

The haemodynamic events during the cardiac cycle are best displayed by plotting the instantaneous left ventricular pressure versus volume [15]. Under steady-state conditions, this pressure-volume loop has a quadrilateral shape where each side represents one of four functional distinct phases: filling, isovolumic contraction, ejection and isovolumic relaxation. End-diastole and end-systole are identifiable as the single pressure-volume points in the lower right-hand and upper left-hand corners, respectively. However, ventricular depolarisation overlaps the rapid rise in intraventricular pressure that marks the onset of ventricular systole. The conductance signal artefact identified in this study meant that end-diastole could no longer be reliably identified on the pressureconductance volume loop alone.

End-diastole may alternatively be defined using the surface electrocardiogram as the onset of the QRS complex [16]; the R wave peak [17]; or up to $40 \mathrm{~ms}$ after the $\mathrm{R}$ wave peak [18]. End-diastole may also be defined as the $\mathrm{R}$ wave peak on the ventricular electrogram. In our experience, this time-point occurs synchronously with the onset of ventricular systole [19]. However, conductance volume measurements at all of these time-points will be variably affected by the conductance signal artefact such that end-diastolic volume cannot be accurately measured using the conductance catheter technique. This in turn means that indices of ventricular function that are based on EDV, such as cardiac output, ejection fraction together with the quantitative assessment of ventricular compliance, will be adversely affected as a consequence of the conductance signal artefact.

\section{STUDY LIMITATIONS}

The limitations of the physical model have been described previously [10]. Electrical activity within the ventricle was represented using a fixed dipole within the ventricular cavity. This comparatively simple model enabled characterisation and quantification of a new conductance measurement error. However, the model did not include any representation of the ventricular wall and the effect of parallel conductance was not examined. A moving dipole or multiple dipoles within an artificial ventricular wall would also have provided a more physiological model.

\section{CONCLUSIONS}

This study has demonstrated that the accuracy of these conductance volume measurements is adversely affected by other electrical signals, such as the ventricular electrogram. The ventricular electrogram produced a clinically important volume measurement that meant enddiastole could neither be precisely identified nor accurately measured. These original findings have important implications for the quantitative assessment of ventricular function and, in particular the assessment of chamber compliance.

\section{ACKNOWLEDGEMENTS}

Simon McGuirk was supported by a British Heart Foundation Junior Research Fellowship (FS/03/102).

\section{REFERENCES}

[1] Baan, J., Aouw Jong, T. T., Kerkhof, P. L., Moene, R. J., van Dijk, A. D., van der Velde, E. T., and Koops, J. (1981) Continuous stroke volume and cardiac output from intraventricular dimensions obtained with an impedance catheter, Cardiovascular Research, 15, 328-334.

[2] Mur, G. and Baan, J., (1984) Computation of the input impedances of a catheter for cardiac volumetry, IEEE Transactions on Biomedical Engineering, 31, 448-453.

[3] Kass, D. A., (1992) Clinical evaluation of left heart function by conductance catheter technique, European Heart Journal, 13(Suppl E), 57-64.

[4] Wu, C. C., Skalak, T. C., Schwenk, T. R., Mahler, C. M., Anne, A., Finnerty, P. W., Haber, H. L., Weikle II, R. M. and Feldman, M. D., (1997) Accuracy of the conductance catheter for measurement of ventricular volumes seen clinically: Effects of electric field homogeneity and parallel conductance, IEEE Transactions on Biomedical Engineering, 44, 266-277.

[5] Salo, R. W., (1989) The theoretical basis of a compartmental model for the determination of volume by impedance, Automedica, 11, 299-310.

[6] Wei, C. L., Valvano, J. W., Feldman, M. D., and Pearce, J. A., (2005) Nonlinear conductance-volume relationship for murine conductance catheter measurement system, IEEE Transactions on Biomedical Engineering, 52, 654661.

[7] Salo, R. W., Wallner, T. G., and Pederson, B. D., (1986) Measurement of ventricular volume by intracardiac impedance: Theoretical and empirical approaches, IEEE Transactions on Biomedical Engineering, 33, 189-195.

[8] Baan, J., van der Velde, E. T., de Bruin, H. G., Smeenk, G. J., Koops, J., van Dijk, A. D., Temmerman, D., Senden, J., and Buis, B., (1984) Continuous measurement of left ventricular volume in animals and humans by conductance catheter, Circulation, 70, 812-823.

[9] Al-Khalidi, A. H., Townend, J. N., Bonser, R. S., and Coote, J. H., (1998) Validation of the conductance catheter method for measurement of ventricular volumes under varying conditions relevant to cardiac surgery, American Journal of Cardiology, 82, 1248-1252.

[10] McGuirk, S. P., Barron, D. J., Ewert, D., and Coote, J. H., (2009) Calibrating volume measurements made using the dual-field conductance catheter, Journal of Biomedical Science and Engineering, In Press.

[11] Durrer, D., Van Dam, R. T., Freud, G. E., Janse, M. J., Meijler, F. L., and Arzbaecher, R. C., (1970) Total excitation of the isolated human heart, Circulation, 41, 899912.

[12] Taccardi, B., Arisi, G., Macchi, E., Baruffi, S., and Spaggiari, S., (1987) A new intracavitary probe for detecting the site of origin of ectopic ventricular beats during one 
cardiac cycle, Circulation, 75, 272-281.

[13] Khoury, D. S. and Rudy, Y. (1992) A model study of volume conductor effects on endocardial and intracavitary potentials, Circulation Research, 71, 511-525.

[14] Derfus, D. L., Pilkington, T. C., Simpson, E. W., and Ideker, R. E., (1992) A comparison of measured and calculated intracavitary potentials for electrical stimuli in the exposed dog heart, IEEE Transactions on Biomedical Engineering, 39, 1192-1206.

[15] Burkhoff, D., Mirsky, I., and Suga, H., (2005) Assessment of systolic and diastolic properties via pressure-volume analysis: A guide for clinical, translational, and basic researchers, American Journal of PhysiologyHeart and Circulatory Physiology, 289, H501-H512.

[16] Roelandt, J. and Gibson, D. G., (1980) Recommendations for standardization of measurements from M-mode echocardiograms, European Heart Journal, 1, 375-378.
[17] Sugeng, L., Mor-Avi, V., Weinert, L., Niel, J., Ebner, C., Steringer-Mascherbauer, R., Schmidt, F., Galuschky, C., Schummers, G., Lang, R. M., and Nesser, H-J., (2006) Quantitative assessment of left ventricular size and function: Side-by-side comparison of real-time three-dimensional echocardiography and computed tomography with magnetic resonance reference, Circulation, 114, 654-661.

[18] Møgelvang, J., Thomsen, C., Mehlsen, J. Bräckle, G., Stubgaard, M., and Henriksen, O., (1986) Evaluation of left ventricular volumes measured by magnetic resonance imaging, European Heart Journal, 7, 1016-1021.

[19] Al-Khalidi, A. H., Lewis, M. E., Townend, J. N., Bonser, R. S., and Coote, J. H., (2001) A novel and simple technique to allow detection of the position of the R-waves from intraventricular pressure waveforms: application to the conductance catheter method, IEEE Transactions on Biomedical Engineering, 48, 606-610. 